\title{
TRABALHO DECENTE PARA PESSOAS COM DEFICIÊNCIA E INCLUSÃO NO MERCADO DE TRABALHO ${ }^{1}$
}

\author{
Patrick Verfe Schneider (D)2, Cibele Roberta Sugahara (D)3, Bruna Angela Branchi \\ (iD4, Edson Keyso de Miranda Kubo iD 5
}

Resumo: O Brasil no início dos anos de 1990 destacou-se no cenário internacional pela adoção de ações afirmativas para pessoas com deficiência junto a empresas com mais de 100 profissionais em seus quadros de lotação. Esta pesquisa de natureza qualitativa e exploratória analisou as práticas adotadas por empresas em relação à inclusão social da pessoa com deficiência no mercado de trabalho, por meio da visão dos gestores de profissionais com deficiência a fim de apontar como a lei de cotas (8.213/91) contribui para o Objetivo de Desenvolvimento Sustentável orientado para o trabalho decente (n.8 da Agenda 2030). Como resultados a pesquisa identificou que há uma intersecção parcial entre a lei de cotas e o objetivo n.8 do ODS. Uma vez que a pessoa com deficiência consegue uma função remunerada, o elemento equidade demonstra-se uma barreira a ser transposta pelo universo laboral no que tange à progressão de carreira.

Palavras-chave: Pessoas com deficiência; Trabalho decente; Ações afirmativas; Inclusão social; ODS 08.

\section{DECENT WORK FOR PEOPLE WITH DISABILITIES AND INCLUSION IN THE LABOR MARKET}

Abstract: Brazil in the early 1990s stood out on the international scene for adopting affirmative actions for people with disabilities in companies with more than 100 professionals in its staffing. This qualitative and exploratory research analyzed the practices adopted by companies in relation to the social inclusion of people with disabilities in the labor market, through the view of managers of professionals with disabilities in order to point out how the quota law $(8,213$ / 91) contributes to the Sustainable Development Goal oriented towards decent work ( $\mathrm{n} .8$ of the 2030 Agenda). As a result, the research identified that there is

\footnotetext{
${ }^{1}$ Parte desse trabalho é resultante da pesquisa desenvolvida na dissertação intitulada O labor da pessoa com deficiência: Intersecções entre a lei de cotas e o preconizado pelo trabalho decente frente a Agenda 2030.

2Mestre em Sustentabilidade pelo Centro de Economia e Administração da Pontifícia Universidade Católica de Campinas (PUC/Campinas). E-mail: patrick.verfe@gmail.com.

${ }^{3}$ Doutora em Ciência da Informação pela Universidade de São Paulo (USP). Professora e Pesquisadora do Programa de Pós-Graduação em Sustentabilidade da Pontifícia Universidade Católica de Campinas-SP (PUC/Campinas). E-mail: cibelesu@puc-campinas.edu.br.

${ }^{4}$ Doutora em Economia Política pela Università Degli Studi Di Pavia, Itália. Professora e Pesquisadora do Programa de Pós-Graduação em Sustentabilidade da Pontifícia Universidade Católica de Campinas (PUC/Campinas). E-mail: bruna.branchi@puc-campinas.edu.br.

${ }^{5}$ Doutor em Administração pela Fundação Getúlio Vargas (FGV/EAESP). Professor do Programa de Pós-Graduação (PPGA)-Mestrado e Doutorado da Universidade Municipal de São Caetano do Sul (USCS). E-mail: edson.kubo@online.uscs.edu.br.
} 
a partial intersection between the quota law and the SDG objective n.8. Once the person with a disability achieves a paid function, the element of equity proves to be a barrier to be overcome by the workforce in terms of career progression, as recommended by the Sustainable Development Goal number 08.

Keywords: People with disabilities; Decent work; Affirmative actions; Social inclusion; SDG 08.

\section{Introdução}

É notória a contribuição da lei de cotas materializada pela Lei 8.213/91 ao trazer visibilidade à sensível condição das pessoas com deficiência (PCD) quanto ao acesso ao mercado de trabalho.

A participação das empresas nesta jornada foi em muitos momentos questionada, haja vista que, durante boa parte dos anos de 1990, poucos foram os movimentos no sentido de cumprimento da estipulada cota e mudança do status quo das PCD em idade laboral (PASTORE, 2000; BAHIA, 2006; GOLDFARB, 2007).

O estímulo definitivo a adesão das organizações ao modelo de cotas teve um marco fundamental no ano de 1999, ano em que foi promulgada a Lei 3.298/99, onde ficou definida a responsabilidade fiscalizatória do Ministério Público quanto ao cumprimento da cota (BRASIL, 1999; GOLDFARB, 2007).

A adoção de ações afirmativas no país representa uma significativa novidade ao inaugurar um movimento inclusivo de grupos postos compulsoriamente à margem de regulares atos da vida como o trabalho, a educação, o lazer e outros fundamentos dos normais atos da vida (GOMES, 2001; BAHIA, 2006; FONSECA, 2006; LARAIA, 2009).

A Organização Internacional do Trabalho (OIT) propõe uma agenda pautada no respeito da dignidade dos seres humanos, quanto a sua posição de desvantagem em uma relação de comando e controle de seu empregador. Tal agenda orientada para o trabalho decente foi recepcionada pela Agenda 2030 através do Objetivo de Desenvolvimento Sustentável (ODS) número 08, intitulado Trabalho Decente e Crescimento Econômico.

A agenda global, proposta pela Organização das Nações Unidas (ONU) no ano de 2015, busca o enfrentamento de temas como fome, desenvolvimento sustentável, a paz social e os desafios da equidade ao redor do mundo, posicionando o ODS 08 como um horizonte a ser perseguido por todas as nações ligadas à ONU (SACHS, 2009b; AGOSTO et al., 2018).

Fundamentado nessa afirmação, faz-se necessário o entendimento de que a dimensão trabalho decente é de fato um direito do trabalhador, colocando a disposição do empregado elementos basilares da função social do trabalho, dentro da sociedade contemporânea, elevando este, como um membro cativo dos direitos fundamentais de todos os seres humanos (BOBBIO, 1992).

Diante do exposto torna-se relevante investigar se a lei de cotas para pessoas com deficiência é suficiente para assegurar a geração de condições (ou relações) de trabalho decente e o desenvolvimento de relações inclusivas no ambiente de trabalho rumo ao defendido pelo ODS 8 . O presente estudo tem 
como objetivo apontar a práticas adotadas por gestores de pessoas com deficiência em relação à inclusão da pessoa com deficiência no mercado de trabalho.

\section{A pessoa com deficiência no mercado de trabalho}

Atualmente importantes discussões sobre a temática da inclusão da pessoa com deficiência na sociedade por meio do mercado de trabalho giram em torno do desenvolvimento humano, a plena inclusão ao ambiente laboral da empresa contratante, a promoção da liberdade no local de trabalho, a progressão de carreira e equidade salarial em mesmo nível dos demais colegas que não possuem uma aparente limitação.

Ao ter como referência as discussões capturadas pelos 17 Objetivos de Desenvolvimento Sustentável (ODS), agrupados através da chamada Agenda 2030 da Organização das Nações Unidas (ONU), principalmente em seu objetivo número 8 denominado "Trabalho Decente e Crescimento Econômico", tem-se 10 metas que em síntese, buscam: a redução da lacuna existente quanto ao acesso ao trabalho à minorias, o crescimento econômico como alavancador do desenvolvimento sustentável, a promoção do trabalho decente e a equidade de tratamento quanto a gênero, raça e pessoas com deficiência.

As práticas integratórias são o primeiro passo no processo de socialização da PCD, oportunizando uma visão da sociedade voltada a exploração das potencialidades do indivíduo, mas que coloca a pessoa com deficiência em uma necessidade de adaptar-se a um diário enfrentamento e convivência com barreiras arquitetônicas e atitudinais comuns ao ambiente laboral (BAHIA, 2006; VEIGA, 2013; SILVA; BERNADINELI, 2017).

Schein (2009, p. 161) define o valor da diversidade dentro das organizações, como algo a ser interpretado a partir da afirmativa:

\footnotetext{
que a natureza humana é complexa e maleável que não se pode fazer uma declaração universal sobre ela" ao contrário, "deve-se estar preparado para a variabilidade humana" que contribui com o desenvolvimento da cultura organizacional, tornando-a plural, desde que alinhada com os gestores da empresa, onde em caso o contrário "resultarão práticas inconsistentes e confusão (SCHEIN, 2009, p. 161).
}

A expectativa de Ulrich et al. (2014, p. 242-246) é de que "os profissionais de RH precisam ser mais sensíveis à demografia global" como agentes de mudança sendo "necessário respeitar as pessoas com experiências diferentes, mas também conectar essas diferenças na organização", a fim de potencializar o valor da diversidade na cultura como "algo que separará as empresas do futuro, das empresas do passado". Muito embora haja nesta citação de Ulrich et al. (2014) uma conotação gerencialista, no sentido de instrumentalizar a utilização da diversidade a favor da competitividade empresarial, observa-se uma preocupação maior do RH com as diferenças e minorias nas organizações contemporâneas (BARRENA-MARTÍNEZ; LÓPEZ-FERNÁNDEZ; ROMEROFERNÁNDEZ, 2019). 
Decodificar de modo valorativo os impactos de se "abraçar" a diversidade, mais do que apenas aceitá-la, ou ainda, tolerar que existirão pessoas diferentes de si dentro de uma organização, torna a cultura organizacional ainda mais produtiva e, ao fim do dia, ainda mais humana (BECKER et al., 2001; BARRENAMARTÍNEZ; LÓPEZ-FERNÁNDEZ; ROMERO-FERNÁNDEZ, 2019).

Quando se discute inclusão, deve-se pensar que todas as pessoas com deficiência podem executar atividades sociais desde que o ambiente ao redor seja adaptado a sua limitação (NERI, 2003). As potencialidades da PCD devem ser exploradas em um ambiente que permita tal prática, sendo compatível à atividade e sua limitação.

No entendimento de Neri (2003, p. 20), para que possa ser identificada a inclusão ao invés da integração, seria necessária a derrubada de barreiras funcionais (adaptações prediais e acomodações de estrutura do ambiente) e sociais (preconceito, discriminação e o mito da ineficiência) garantindo à pessoa com deficiência uma libertação do estado de desvantagem em relação as demais pessoas.

A partir da leitura do apresentado, entende-se que, quando se pensa em integração enxerga-se que o indivíduo deve mudar, que o problema está nele, e que ele deve acompanhar o mundo ao redor do modo que ele está posto. Totalmente diferente do entendimento do termo inclusão, que prevê uma mudança/adaptação no ecossistema, possibilitando a todos, o desenvolvimento de sua cidadania, tendo ou não deficiência.

Neste sentido, entende-se que a partir da adoção de ações afirmativas, com a promulgação de reserva de posições profissionais em empresas, a caminhada rumo à equiparação de oportunidades está iniciada. Entretanto se faz fundamental um aprofundamento sobre este tema, e uma maior reflexão quanto ao cumprimento do objetivo principal da adoção destas medidas - a inclusão da pessoa com deficiência no Brasil.

\section{Metodologia}

A pesquisa tem abordagem qualitativa e exploratória. Busca-se diagnosticar as práticas adotadas para o trabalho decente e inserção da pessoa com deficiência no mercado de trabalho, tendo em vista a lei de cotas e o ODS n. 8 da Agenda 2030.

O escopo da unidade de análise e coleta de dados foi definido com base nas recomendações de Yin (2001). Essa pesquisa vale-se da estratégia de estudos de casos que possibilitam investigar um fenômeno da vida real, sobretudo para realizar uma generalização analítica. A investigação contou com duas empresas multinacionais, líderes de mercado em seus segmentos de máquinas e implementos com aplicações agrícolas, na área de infraestrutura e no tratamento florestal, situadas no estado de São Paulo, que por sua vez, são consideradas referência no Brasil nos temas diversidade e inclusão da pessoa com deficiência, reconhecidas pelo "Guia Exame de Diversidade e Inclusão" do ano de 2019.

Com base nas orientações de Yin (2001) a seleção das pessoas incluídas no grupo atende ao critério de possuírem características particulares daquelas que 
estão fora dele. Assim, compõem a amostra intencional 12 gestores de pessoas com deficiência, sendo que predominam gestores com formações na área de Engenharia. Desse conjunto, $42 \%$ estão vinculados à primeira empresa e 58\% à segunda.

Procedeu-se a seguir com entrevistas realizadas de forma presencial nas dependências das empresas estudos de caso em 2020. O tratamento e análise dos dados foi elaborado a partir da técnica da análise de conteúdo com base em Bardin (2016).

A análise categorial foi elaborada a partir da análise e leitura do conteúdo das entrevistas, de onde se propôs unidades de codificação advindas da repetida ocorrência de palavras na fala dos entrevistados. Esse critério embasou a criação de categorias iniciais e subcategorias, sendo estas emergentes a partir da fala livre e espontânea de cada entrevistado, capturada pelo pesquisador, consoante ao proposto por Bardin (2016).

Por conseguinte, todas as categorias e subcategorias, foram elaboradas pós-fato, e o agrupamento foi realizado considerando a aproximação de conteúdos analogamente afeitos entre si. As categorias oriundas do grupamento de percepções dos gestores das empresas contemplaram: a) processo seletivo e contratação de PCD, envolvendo sua qualificação, compreensão de sua limitação e receptividade da equipe; b) Desenvolvimento, contemplando a preparação da liderança e do time, a integração e inclusão do PCD; c) Manutenção e conservação do posto de trabalho, abrangendo a estabilidade, gestão de performance e segurança quanto à progressão na carreira e d) equidade, em termos de remuneração, diversidade e tratamento.

$\mathrm{Na}$ próxima seção são analisados os resultados da pesquisa a partir de evidências argumentativas e objetivas do conteúdo coletado em relação às unidades textuais.

\section{Resultados e discussões}

4.1 Categoria 1 - Processo seletivo e contratação de PCD

Para Schein (2009, p. 148-150) enquanto o "processo seletivo possui função prioritária quanto a identificação de pessoas com aptidões chave para ocupar uma função" cabe aos gestores a tarefa de "identificar e aprovar aqueles que possuem maior similaridade quanto ao proposto pelo candidato e pela empresa" Ter uma visão preparada para conseguir atender a esta expectativa é uma das muitas questões ligadas à inclusão de um novo talento ao grupo empresarial.

Os representantes das empresas, manifestaram através das falas, que a intenção das companhias é sempre ter as pessoas alinhadas em termos de capacidades aos desafios propostos como pode ser evidenciado através da fala do G09: 
A preocupação das companhias com a função social, frente o ecossistema empresarial o qual está inserida é algo presente nas empresas pesquisadas, isso pode ser concretizado pelas expressões colhidas nas entrevistadas, como relatado pelo G06:

A pessoa que passa por entrevista comigo [...] sempre é questionada qual o entendimento dela quanto a sua deficiência [...] Pergunto isso por que a deficiência ela não pode estar nem na sua mente, nem no coração, se não a limitação será ainda maior do que de fato ela é, tem que ser apenas uma deficiência física $[\ldots]$.

As práticas integratórias devem ser consideradas o primeiro passo para a inclusão social, entretanto para que se consiga progredir de modo virtuoso rumo a inclusão social. Neste sentido a criticidade da avaliação ambiental é um momento vital na contratação de uma pessoa com deficiência (BAHIA, 2006; SILVA e BERNADINELI, 2017).

Pensar a inclusão sob a ótica das adaptações estruturais realizadas nas organizações, permite compreender que são necessários ajustes físicos propiciando o acesso da PCD às condições necessárias para uma entrega valorativa e comparável com o conteúdo de trabalho de uma pessoa que não possui aparente limitação física ou intelectual para o desempenho de sua atividade. Este conjunto de equipamentos inclusivos devem ser percebidos pela liderança como algo fundamental para que o profissional com deficiência possa desempenhar o seu papel com segurança nas dependências da empresa.

Para que a PCD seja incorporada ao time de trabalho e para que as práticas inclusivas sejam potencializadas, foi verificado como são tratadas as avaliações do posto de trabalho e do ambiente laboral, para que sejam atendidas as necessidades das organizações pesquisadas, bem como da pessoa com deficiência, ora contratada: G07 - "Eu gosto sempre de alinhar com o RH e com a área de Saúde, Segurança e Meio Ambiente quais os limites de esforço e coisas do tipo [...] tudo o que não quero é que a pessoa prejudique a sua saúde no trabalho.".

Conseguir acessar a este arcabouço, presente em todas as pessoas independente de sua condição física ou intelectual, precisa ser o entendimento de todos os envolvidos em um processo de seleção para $P C D$, desde o seu princípio (GOLDFARB, 2007; SÉGUIN, 2002).

Cabe a reflexão, com base nos relatos capturados nas entrevistas, sobre a carga recebida pelas empresas, advindas das famílias e das próprias pessoas com deficiência, quanto a sua absorção no ambiente organizacional, independentemente de fatores psicológicos e auto aceitação da PCD quanto a extensão de sua condição limitante e suas virtudes a serem colocadas a serviço de uma posição remunerada.

Os relatos colhidos neste tópico revelam um alinhamento com o ODS 08, principalmente na meta 8.5 fortemente quanto ao acesso ao "emprego pleno e produtivo e trabalho decente" fortalecendo ainda a busca por incluir as "pessoas com deficiência" em suas ambições de acesso a "remuneração igual para o trabalho de igual valor". 


\subsection{Categoria 2 - Desenvolvimento}

Uma das alternativas sugerida pelos gestores para que sejam contornadas, tanto as oportunidades, como as dificuldades trazidas pelo processo de seleção, é o investimento em desenvolvimento das pessoas envolvidas na contratação e no desempenho de atividades junto a pessoa com deficiência.

Garantir que toda a comunidade de sustentação da PCD contribua na manutenção de sua motivação e inclusão nas atividades dependem do investimento em capacitação dos times, líderes e demais pessoas presentes na empresa (ARAÚJO e SCHMIDT, 2006; BAHIA, 2006).

Estas afirmativas ficam claras através das falas dos gestores, transcritas a seguir: G03 - "Treinar e sensibilizar a todos para que a pessoa se sinta acolhida é uma ação que tem contribuído [...] em outras experiências que tive, as lideranças não deixavam tão claramente qual era a nossa responsabilidade enquanto gestores, estas sensibilizações não deixam dúvidas quanto as expectativas.". G06 - "Muita instrução e muito diálogo, com o time e com o novo funcionário [...]. Não o colocar como uma peça especial dentro da equipe, você não tratar ele como uma pessoa especial, ele precisa ser tratado como todos $[\ldots]^{\prime \prime}$.

Conforme leciona Ribas (2003, p. 16-19) quando o mundo, nos diferentes cenários, passa a "visualizar a presença da pessoa com deficiência dentro da sociedade ela passa a aprender junto com estas pessoas o valor de conceder espaço" para que todos possam conviver de modo harmonioso.

Neste contexto, os incentivos à construção de uma sociedade inclusiva não devem se limitar à relação de trabalho, ou à necessidade de atendimento de uma cota laboral, mas devem se estender para dentro da sociedade apontando que existem "cotas" para PCD fora das empresas.

Justamente por força das percepções dos ganhos com os processos de desenvolvimento, estes vão para além da liderança, progredindo para os colegas no entorno do PCD, como exemplificado pelos trechos colhidos a seguir: G01 "Quando começaram a ocorrer as sensibilizações eu tinha que forçar um pouco o assunto com meu grupo, percebia pouca motivação [...] eu enxergo muita mudança no meu time no que diz respeito a empatia hoje.". G11 - "Os treinamentos trazem para o nível de consciência coisas que achamos que sabemos, mas que na verdade somos movidos pelos vieses que todos nós carregamos internamente[.]".

A partir das falas dos entrevistados observa-se a importância de construir uma rede de sustentação para a PCD após a sua contratação permitindo que a experiência dentro de uma organização possa ser duradoura e frutífera, pavimentando uma carreira profissional da qual a pessoa com deficiência orgulhe-se, deseje evolucionar-se e cada vez mais sinta-se parte da sociedade a qual está inserida (NERI, 2003; LARAIA, 2009).

A parcela que cabe a esta categoria, denominada desenvolvimento, pesa em muito no sucesso da inserção da PCD no mercado de trabalho, tendo em vista, que a preparação do entorno do indivíduo exige tanta ou mais atenção que as próprias exigências profissionais atribuídas as competências de um profissional PCD para ocupar um cargo de trabalho. 


\subsection{Categoria 3 - Manutenção e conservação do posto de trabalho}

Uma dimensão que caracteriza uma relação laboral como digna ou decente é que as pessoas devem sentir-se seguras dentro do ambiente laboral, sem contarem com a ameaça constante da perda potencial de sua ocupação (ARAÚJO, 2017; RIBEIRO, 2019; SACHS, 2019 a).

Fica evidente através da fala transcrita a seguir que os gestores percebem esta situação como algo que pode ser prejudicial para a PCD e para a empresa, caso não seja bem gerenciado. G05:

A empresa pode prejudicar-se caso o profissional não compreenda que a performance é um elemento-chave para a permanência na companhia [...] isto é um item que não podemos nos omitir jamais, principalmente para um PCD [...] que pode, não digo que todos são assim, mas eles (PCDs) as vezes confundem a cota com estabilidade e são coisas distintas uma coisa da outra.

As questões relacionadas a gestão adequada da performance, também, é um fator fundamental para que o profissional, independe de ter uma limitação ou não, possa sentir-se compromissado e entendendo as possibilidades de progressão de carreira dentro da empresa (ELKINGNTON, 2012; COUTINHO et al., 2017; COHEN; MOODLEY, 2012).

Desta forma, percebe-se que as empresas pesquisadas possuem os processos estruturados o que beneficia a gestão e avaliação da performance, apoiando assim a progressão dentro da carreira desempenhado pelo profissional. Esta afirmativa pauta-se na narrativa apresenta a seguir: G06:

O que a gente trabalha, e acho que isso muito das empresas de modo geral, o que queremos é a busca pelo crescimento profissional das pessoas [...] então, não é por que ela entra em uma função que ela vai ficar somente limitada aquela atividade [...]. A parte inclusiva é você vislumbrar o crescimento desta pessoa com deficiência em outras atividades e isso a gente pratica [...]. Esta avaliação ela é a mesma independentemente de ser PCD ou não e o formulário padrão ele é explicado e compartilhado com todos no início de cada ciclo, para que as regras sejam claras para todos $[\ldots]$.

O compromisso com o desempenho individual dos seus liderados é um comportamento chave para que o progresso, almejado pelo time, possa ser uma realidade dentro das organizações (FREITAS; MARQUES, 2009).

Apontar os caminhos a serem seguidos pela pessoa com deficiência dentro da organização, garantindo um retorno concreto sobre a sua performance, colabora em muito no ganho da estabilidade da relação de trabalho. A fala a seguir demonstra como é enfrentado o tema internamente: G12:

Duas vezes por ano eu converso sobre a performance e o feedback ele é entregue tentando colocar as pessoas nos trilhos [...] existem vezes que nós temos que ser um pouco mais firmes, mas sempre demonstrando que só depende deles ter uma carreira longa na empresa [...] feedback é um presente que se dá ao outro. 
Assim, o papel do líder em transmitir certezas para o seu grupo de liderados colabora em muito com o senso de pertencer e segurança frente a ameaças arbitrárias de um empregador menos engajado com estas temáticas (ALVARENGA, 2016; GALVÃO; LEMOS; CAVAZOTTE, 2018).

Permitir que o profissional possa fazer planos de longo prazo, bem como possa desenvolver-se para além do momento atual, são características de empresas que se preocupam com o bem-estar e a manutenção dos postos de trabalho, preocupando-se ao fim do dia com as pessoas que ali entregam o seu melhor diariamente, através da função laboral. No mesmo sentido alinham-se ao espírito proposto pelo ODS 08 quando este direciona-se a promoção do "crescimento econômico sustentado, inclusivo e sustentável" pautando ações para o acesso a uma remuneração justa e igualitária, independentemente de marcadores sociais.

\subsection{Categoria 4 - Equidade}

O tratamento pautado na equidade demonstrou-se preservado pelas empresas entrevistadas, como pode ser exemplificado a partir da fala de um dos gestores entrevistados: G10 - "Eu não trabalharia em uma empresa que não fosse igualitária [...] todo o dia que começo por aqui o meu nome está indo junto do nome da empresa [...] ser igualitário no tratamento para mim é um valor e fazemos bem por aqui isso [...] de modo natural.".

Houve ainda relatos de que as empresas compartilham as informações dos negócios e existem rotinas regulares de retorno sobre o desempenhado por cada profissional, concretizando na prática de que cada profissional possui uma medição única sobre as suas entregas conforme exemplificado na fala do G06 "Eu converso com todos eles, onde compartilho a saúde da empresa, dúvidas e informações são sanadas diariamente [...] eu estou sempre próxima, perguntando se eles precisam de algo dentro da área, constantemente vou verificar se a função está adequada para a sua deficiências [...] o que mais me preocupa é que o PCD pense que está fazendo atividades que não deveriam ser desempenhadas por ele [...] só por ser PCD [...] regularmente eles recebem feedback sobre a performance e as condições em que estão sendo percebidos por mim e meus superiores[...].".

Cada vez mais emerge dentro das organizações o valor da diversidade e pluralidade de formas de agir e pensar, contribuindo em muito com o processo evolutivo. Esta é a visão de vários autores sobre uma temática atual e crescente no mercado de trabalho, em muitos casos atreladas à inovação e a concretização de um futuro frutífero para todas as organizações (ARAUJO, 2017; GALVÃO, LEMOS; CAVAZOTTE, 2018).

A partir da leitura dos parágrafos anteriores compreende-se o valor prático da palavra equidade dentro das organizações, a partir do tratamento junto e não discricionário de onde os gestores compreendem seu papel na jornada evolutiva para que uma sociedade plural, pautada na diversidade.

Os instrumentos para garantir a igualdade de tratamento e a diversidade dentro do time foram compartilhadas na sequência, formando um comportamento presente durante as falas completas dos entrevistados, mas que 
merece destaque quanto aos trechos a seguir: G03 - "Se todos forem iguais no time a empresa sai perdendo, a diferença é que nos fortalece [...] eu tento mostrar isso ao departamento.". G10 - "Estou sempre incentivando eles (PCDs) a se candidatarem em recrutamentos internos, mesmo aqueles que não são da minha área, fico instigando para que estudem os temas com os quais trabalhamos aqui [...] alguns mostram interesse [...] mas não é a maioria o que é uma pena $[. . .]^{\prime \prime}$

O tratamento equitativo dentro das equipes de trabalho deve ser um compromisso diário da liderança. Em grupos industriais onde os times podem ser compostos por dezenas de pessoas, acredita-se que o desafio da liderança seja ainda maior. No entanto, esta é uma forma virtuosa de construir um ambiente seguro para que a PCD possa sentir-se parte e desfaça qualquer crença limitante que impeça seu crescimento econômico e individual (SASSAKI, 2003; SANTOS, 2018).

Através da equidade, renova-se a crença da pessoa com deficiência de que ela é bem-vinda e que está sendo convidada a interagir, através de uma função profissional. Deste modo, funcionários e empresas poderão beneficiar-se de um ambiente de referência no tratamento igualitário, podendo diminuir a dificuldade pela busca de profissionais em um mercado cada vez mais competitivo que é o universo de contratação de um profissional com deficiência (OIT, 1994; SEGUIN, 2002; FONSECA, 2006; COSTA, 2016; OIT, 2019).

No entanto, há de se compreender que este exercício de garantir as mesmas condições em escalas diferentes, mas que permitam fazer com que as pessoas não estejam em desvantagem, ou pelo menos não a percebam como tal, passa a figurar as preocupações dos bons líderes. Parece algo pouco relevante, mas como percebido nas duas últimas falas capturadas e compartilhadas no presente estudo, o desafio da promoção da equidade deve sair da lista de preocupações dos PCD e passar a figurar a lista de prioridades da liderança, garantindo assim, que a sociedade e o mercado de trabalho passarão a evoluir rumo a inclusão social da pessoa com deficiência através do mercado de trabalho e que assim, possa estar próxima do defendido pela Agenda 2030 em relação a equidade social associada ao trabalho decente.

Por fim, pode-se compreender, a partir dos trechos colhidos nas entrevistas, que estes relatos aproximam-se do ODS 08 e sua ambição que descreve o que é objetivo orientado ao trabalho decente como um instrumento para "promover o crescimento econômico sustentado, inclusivo e sustentável" colaborando especialmente com a meta 8.8 que prevê a proteção dos direitos trabalhistas e visa "promover ambientes de trabalho seguros protegidos para todos os trabalhadores" independente de sua condição singular.

\section{Considerações finais}

Ter um horizonte de crescimento pautado em certezas de um futuro na organização permite ao profissional planejar a sua vida, organizando-se para um ambiente que não lhe tem apenas pela cota ou por uma exigência legal, mas sim permitindo concretizar um elemento-chave para o trabalho decente pautado nas liberdades reais das pessoas. 
Um componente chave no acesso ao mercado de trabalho por PCD é o desenvolvimento de suas competências antes mesmo de candidatar-se a uma posição dentro de uma empresa. Tornar este ciclo de desenvolvimento através de treinamentos, sensibilizações e experiências vivenciais de desenvolvimento, mostrou-se relevante através da fala dos gestores entrevistados.

Dentre todos os desafios enfrentados pela PCD, talvez a equidade, seja a maior barreira, como mencionado na presente pesquisa, contudo a OIT desde 1999 vem perseguindo esta temática com afinco, como forma de frear o avanço das desigualdades sociais ao redor do mundo, elemento fundamental capturado pela Agenda 2030 através de suas ambições frente ao acesso ao trabalho decente e o crescimento econômico.

A obtenção de um posto de trabalho, ainda que figure um progresso importante introduzido pela lei de cotas, não garante a condição de ascensão econômica a um profissional enquadrado como PCD, independente se este abandona um subsídio governamental ou se está formalmente empregado em uma organização.

No mesmo sentido, o acesso a uma função laboral não garante, ao fim do dia, que esta posição possa ser definida como um trabalho decente, como evidenciado neste estudo. Ao atribuir à PCD postos de trabalho com menor complexidade, de natureza operacional e que não permitem dar visibilidade às potencialidades do agente, em muitos casos pode ser interpretado como a simples criação de um cargo motivada pela obrigação jurídica.

A partir da pesquisa entende-se o comportamento de empresas, consideradas referências na gestão e incentivo da temática Diversidade e Inclusão, calcado na manutenção de boas práticas no que tange a contratação e desenvolvimento de pessoas com deficiência, aponta para uma intersecção parcial do ODS 08 e o pretendido da lei de cotas a partir do mercado de trabalho nacional. Entretanto, deixa uma lacuna quanto as práticas que permitam a evolução sustentável de PCD a partir de uma carreira construída dentro de uma empresa privada.

A pesquisa revela a importância em refletir sobre as práticas adotadas por outras empresas tendo em vista as ações empreendidas pelas empresas deste estudo, no que tange ao desenvolvimento de gestores e times que recebem um profissional PCD em seu contexto laboral, bem como para a própria pessoa com deficiência a quem carece de iniciativas de alavancagem de suas potencialidades. Isso pode contribuir para o acesso ao trabalho digno, sustentado e crescimento econômico de modo consistente para a PCD.

\section{REFERÊNCIAS}

AGOSTO, Gabriela; FONTELA, M.; BRANDY, L.; LANGSAM, Martín. La Agenda 2030 como herramienta de desarrollo para los jóvenes en Argentina. Ciência

\& Saúde Coletiva, v. 23, n. 9, p. 2797-2802, 2018. Disponível em: http://www.scielo.br/scielo.php?script=sci_arttext\&pid=S141381232018000902797. Acesso em: 18 out. 2019. 
ALVARENGA, Rubia Zanotelli de. Trabalho decente: direito humano e fundamental. São Paulo: LTr, 2016.

ARAÚJO, Janine Plaça; SCHMIDT, Andréia. A inclusão de pessoas com necessidades especiais no trabalho: a visão de empresas e de instituições educacionais especiais na cidade de Curitiba. Rev. bras. educ. espec., v. 12, n. 2, p. 241-254, 2006. Disponível em: http://www.scielo.br/pdf/rbee/v12n2/a07v12n2.pdf. Acesso em: 19 jan. 2020.

ARAÚJO, Nina Ferrer. Los nuevos movimientos sociales y las ciudadanías emergentes: reflexiones desde el concepto de democracia radical y el movimiento LGBTI en Colombia. Estud. Socio-juríd., v. 19, n. 1, p. 43-62, 2017. Disponível em: http://www.scielo.org.co/pdf/esju/v19n1/v19n1a03.pdf. Acesso em: 16 fev. 2020.

BARRENA-MARTÍNEZ, Jesús; LÓPEZ-FERNÁNDEZ, Macarena; ROMEROFERNÁNDEZ, Pedro Miguel. Towards a configuration of socially responsible human resource management policies and practices: Findings from an academic consensus. The International Journal of Human Resource Management, v. 30, n. 17, p. 2544-2580, 2019.

BAHIA, Melissa Santos. Responsabilidade social e diversidade nas organizações: contratando pessoas com deficiência. Rio de Janeiro: Qualitymark, 2006.

BARDIN, Lawrence. Análise de conteúdo. São Paulo: Edições 70, 2016.

BECKER, Brian; HUSELID, M. A.; ULRICH, D. Gestão estratégica pessoas com "scorecard": integrando pessoas, estratégias e performance. Rio de Janeiro: Elsevier, 2001.

BOBBIO, N. A era dos direitos. Rio de Janeiro: Campus, 1992.

BRASIL. Lei 3.298 de 20 de dezembro de 1999. Regulamenta a Lei no 7.853 , de 24 de outubro de 1989, dispõe sobre a Política Nacional para a Integração da Pessoa Portadora de Deficiência, consolida as normas de proteção, e dá outras providências. Brasília, DF: Presidência da República. Disponível em: http://www.planalto.gov.br/ccivil_03/decreto/d3298.htm. Acesso em: 21 out. 2019.

COHEN, Tamara; MOODLEY, Luendree. Achieving "decent work" in South Africa? PER, v. 15, n. 2, p. 320-344, 2012. Disponível em: http://dx.doi.org/10.4314/pelj.v15i2.12. Acesso em: 01 mar. 2020.

COSTA, Nilson do Rosário; MARCELINO, Miguel Abud; DUARTE, Cristina Maria Rabelais; UHR, Duarte. Proteção social da pessoa com deficiência no Brasil, Ciência \& Saúde Coletiva, v. 21, n. 10, p. 3037-3047, 2016. Disponível em: 
https://www.abrasco.org.br/site/wpcontent/uploads/2016/11/artigo_nilson_do_rosario.pdf. Acesso em: 01 ago. 2019.

COUTINHO, Kátia Soares; ROGRIGUES, Graciela Fagundes; PASSERINO, Liliana Maria. O trabalho de colaboradores com deficiência nas empresas: Com a voz os gestores de Recursos Humanos. Marília: Rev. Bras. Ed. Esp., v. 23, n. 2, p. 261-278, 2017. Disponível em:

http://www.scielo.br/pdf/rbee/v23n2/1413-6538-rbee-23-02-0261.pdf. Acesso em: 01 ago. 2019.

ELKINGTON, John. Sustentabilidade: Canibais com garfo e faca. São Paulo: M. Books, 2012.

FONSECA, Ricardo Tadeu Marques da. O trabalho da pessoa com deficiência e a lapidação dos direitos humanos: o direito do trabalho, uma ação afirmativa. São Paulo: LTr, 2006.

FREITAS, Mariana Nivalda Carvalho; MARQUES, Antônio Luiz. Trabalho e Pessoas com Deficiência: pesquisas, práticas e instrumentos de diagnóstico. São Paulo: Juruá, 2009.

GALVÃO, Mariana; LEMOS, Ana Heloisa da C. ; CAVAZOTTE, Flavia de S. C. N. Revisiting the mainstream: The meaning of work for people with acquired disabilities. RAM. Rev. Adm. Mackenzie, v.19, n. spe, 2018. Disponível em: http://www.scielo.br/scielo.php?script=sci_arttext\&pid=S167869712018001000604. Acesso em: 01 jul. 2019.

GOLDFARB, Cibele Linero. Pessoas portadoras de deficiência e a relação de emprego: o sistema de cotas no Brasil. Curitiba: Juruá, 2007.

GOMES, Joaquim Benedito Barbosa. Ação afirmativa \& princípio constitucional da igualdade: o direito como instrumento de transformação social. A experiência dos EUA. São Paulo: Renovar, 2001.

LARAIA, Maria Ivone Fortunato. A pessoa com deficiência e o direito do trabalho. 2009. 197f. Dissertação (Mestrado em Direito) - Pontifícia Universidade Católica de São Paulo, São Paulo, 2009.

NERI, Marcelo. Retratos da deficiência no Brasil (PPD). Rio de Janeiro: FGV/IBRE, 2003.

OIT. Organização Internacional do Trabalho. Oportunidades de trabalho para portadores de deficiência: um guia para as organizações de empregadores, Brasília: CORDE, 1994. Disponível em: http://www.ilo.org/public/libdoc/ilo/1992/92B09_477_port.pdf. Acesso em: 01 jul. 2019. 
OIT. Organização Internacional do Trabalho. Work for a brighter future. Global commission on the future of work. Geneva: ILO, 2019. Disponível em: https://www.ilo.org/infostories/en-GB/Campaigns/future-work/globalcommission\#institutions. Acesso em: 09 mar. 2020.

OMS. Organização Mundial da Saúde. Relatório mundial sobre a deficiência. São Paulo, 2011. Disponível em: https://apps.who.int/iris/bitstream/handle/10665/44575/9788564047020_por. pdf; jsessionid $=04618434$ FE154FE3F4F0BA9F9DE53BD7? sequence $=4$. Acesso em: 15 out. 2019.

ONU. Organização das Nações Unidas. Realization of the sustainable development goals by, for and with person with disabilities. United Nations. Department of Economic and social affairs, 2018.

ONU. Organização das Nações Unidas. Nações Unidas Brasil, 2019. Disponível em: https://brasil.un.org/. Acesso em: 08 mar. 2020.

PASTORE, José. Oportunidades de trabalho para as pessoas com deficiência. São Paulo: LTr, 2000.

RIBAS, João Baptista Cintra. O que são deficientes. São Paulo: Brasilense. 2003.

SACHS, Ignacy. A terceira margem: em busca do ecodesenvolvimento. São Paulo: Companhia das Letras, 2009a.

SACHS, Ignacy. Caminhos para o desenvolvimento sustentável. Rio de Janeiro: Garamond, 2009b.

SANTOS, Aline Cristina dos. Inserção laboral das pessoas com deficiência nos Sistema S da cidade de São Carlos. 2018. 193f. Tese (Doutorado em Educação Especial). Universidade Federal de São Carlos, 2018.

SASSAKI, Romeu Kassumi. Vida independente: História, movimento, liderança, conceito, filosofia e fundamentos; reabilitação, emprego e terminologia. São Paulo: RNR, 2003.

SÉGUIN, Elida. Minorias e grupos vulneráveis: uma abordagem jurídica. Rio de Janeiro, 2002.

SEN, Amartya. Desenvolvimento como liberdade. São Paulo: Companhia das Letras, 2010.

SCHEIN, Edgar Henry. Cultura Organizacional e Liderança. São Paulo, Atlas, 2009. 
SILVA, Leda Maria Messias da; BERNARDINELI, Muriana Carrilho. Temáticas do meio ambiente de trabalho digno. São Paulo: LTr, 2017.

ULRICH, David; BROCKBANK, Wayne; YOUNGER, Jon; ULRICH, Mike. Agregando valor competitivo de fora para dentro: Competência globais do RH. Porto Alegre: Bookman, 2014.

VEIGA, José Eli da. A desgovernança mundial da sustentabilidade. São Paulo: Editora 34, 2013.

YIN, Robert K. Estudo de caso: Planejamento e métodos. Porto Alegre: Bookman, 2001.

Recebido em: 31 de maio de 2021. Aceito em: 28 de junho de 2021. Publicado em: 15 de dezembro de 2021. 